\title{
Effects of Hydrogen Fluoride-stress on Physiological Characteristics of Theaceae Tree Seedlings
}

\author{
Baoyi Yang ${ }^{1, a}$, Tonggao Sun ${ }^{1}$, Hongyue Chen ${ }^{* 1}$, Zhiyun Wang ${ }^{2}$,Huixi Yang ${ }^{1}$, \\ Xiongfei Guo ${ }^{1}$, Xiang Chen ${ }^{2}$ \\ ${ }^{1}$ College of Forestry and Landscape Architecture, South China Agricultural University, Guangzhou, \\ Guangdong, China \\ ${ }^{2}$ Foshan Institute of Forestry Science, Foshan, Guangdong, China \\ a356932115@qq.com
}

\begin{abstract}
Keywords: Hydrogen Fluoride; Stress; Theaceae; Chlorophyll Fluorescence; Relative Electrical Conductivity
\end{abstract}

\begin{abstract}
In this study, four Theaceae tree species were processed by setting up two hydrogen fluoride concentration gradient (including controls), the actual quantum yield (Y (II)) of PSII, the relative electron transport rate (ETR), non-regulatory energy dissipation quantum yield (Y(NO)), regulatory energy dissipation quantum yield (Y(NPQ)), non-photochemical quenching coefficient (NPQ) and the relative electrical conductivity and other physiological characteristic value were measured, and fuzzy membership function method was applied for comprehensive evaluation and stress resistance sequencing of these four species, which could help to explore the impact of HFstress on physiological indicators of Theacea tree seedlings, and effectively screen out tress species with high resistance to hydrogen fluoride; besides, it could provide the basis for selection of planting trees with the purpose of environmental protection, and also provide a reference for $\mathrm{HF}$ stress mechanisms study. This study showed that, under the circumstance of 500 ppm hydrogen fluoride stress, chlorophyll fluorescence indicator of Theaceae tree species presented a downward trend on the whole, which concretely embodied in varying degrees of decline of Y (II) of PSII, ETR, Y (NO), Y (NPQ), NPQ. And the cell membranes of trees species were damaged and the membrane permeability increased. Except for Schima superba, the relative conductivity value of other species showed an upward trend. The capacity of these four species in anti- hydrogen fluoride contamination was Tutcheria championi first, Camellia oleifera second, Schima superba third, Gordonia axillaries is the last.
\end{abstract}

\section{Introduction}

Hydrogen fluoride (HF) gas is one of the most toxic air pollutants [Leonard H.Weinstein,1977], which is discharged through brick, fertilizer, cement, smelting and other industrial processes into the atmosphere [Moyer D.Thomas\&Ernest W.Alther,1966], and causes serious damage to the surrounding plants [Fornasiero R B, 2001] . And because HF can be accumulated in leaves of plants [AW Davison, et al., 1984], which could endanger the health of animals and humans through the food chain, and result in insect and virus mutation, human malnutrition and decreased physical function, and other problems [Mamta Baunthiyal et al., 2014]. HF mainly damages the plant by entering into its body in the form of gas and affects a variety of plant physiological processes [Gou Xiaohua et al., 2000], in which, PSII plays an important role in the formation of resisting stress in photosynthetic apparatus [Wei Xiaodong et al., 2012; Baker N R,1991]. And by the application of chlorophyll fluorescence dynamics, we did in-depth analysis of environmental stress impact on PSIIand other chlorophyll fluorescence parameters to screen out tree species with strong resilience.

At present, some studies have done discussing the mechanism how pollutants damage plants and also plant resistance comparison using its physiological characteristics, one example: how ozone affects some physiological indicators of plant [JIN Minghong et al., 2000], photosynthate, biomass [Grantz D A\&Farrar J F, 1999; Dickson R E et al., 1998], chloroplast fluorescence properties and chloroplast fluorescence system II (PSII) [Guera A et al., 2005; Calatayud A et al., 2002]; another 
example: how sulfur, fluoride and heavy metals affect chlorophyll fluorescence of the European thorn pine [Pawet M. Pukacki, 2000] and so on. This implies that we can tell the impact of HF on plants by measuring HF-stressed plant leaf green fluorescence, relative conductivity and other physiological indicators, process and evaluate the data to effectively filter out plant species with certain HF anti-stress, and then select plants with HF-resistance and better absorbing in the surrounding of industrial zone and establish artificial green ecological engineering system of different types. In addition, through the research of biological mechanism on plant anti-stress, we can plant and induce other plant species to provide their anti-pollution ability. Our research could tell how HF anti-stress plants effectively alleviate environmental pollution and improve the ecological environment, and has a great significance to the construction of ecological forest and the achievement of sustainable development of urban forestry.

\section{Materials and Methods}

\subsection{Experimental Field}

It was located on the campus of South China Agricultural University, Guangzhou City. $\left(23^{\circ} 09\right.$ 'N, $113^{\circ} 21^{\prime}$ E). Test objects: The two-year container bag seedlings of Schema superba, Gordonia axillaris, Tutcheria championi and Camellia oleifera of Theacea.

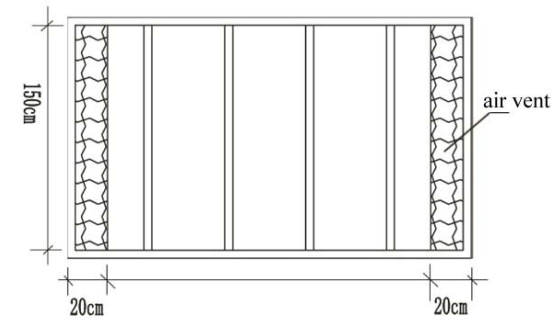

Plan View of Fumigation Room

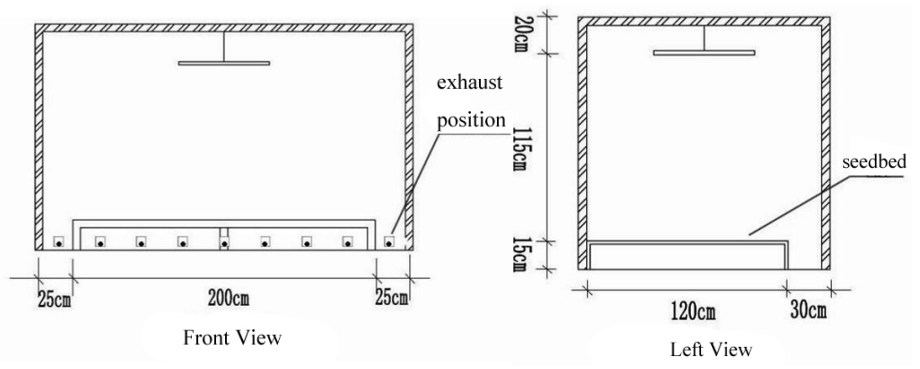

Fig.1 Schematic diagram of fumigation chamber

The experimental fumigation equipment was to simulate the natural dynamic smoke chamber (Fig. 1) with a volume of about $5.6 \mathrm{~m} 3$. The nursery bed for displaying seedlings was placed in the gas chamber with a height of about $15 \mathrm{~cm}$, and a $40 \mathrm{~V}$ fan was equipped to stir gases in the fumigation chamber. Hydrogen fluoride gas was generated from the diffusion of hydrofluoric acid solution placed under the bottom of fumigation chamber, and then was mixed into the airflow blowing from axial flow fan. Then the airflow passed the gas cumber through the nursery bed from bottom to top, and was diffused by the fan to make the gas mass fraction to be equal. The gas was collected by a hand pump, and then the gas mass fraction was measured and monitored using HF detector tube produced by China Sciences Group, with the frequency of once every 2 hours.

We designed this experiment referring to the former research result [Chen Zhuomei et al., 2008], and set up a 500 ppm concentration and a control CK (HF concentration in the ambient atmosphere). During the test, gas of fumigation chamber was in a fluid state and was in a relatively stable controlled concentration. The experiment was conducted in October 2013, with fumigation of $12 \mathrm{~h}$ (7: 00-19: 00). At 9:00-11:30 of the second day after fumigation, we measured chlorophyll fluorescence indicators of leaves, and sheared the fresh leaves to measure the relative conductivity indicators with three replications.

\subsection{Measurements of chlorophyll fluorescence characteristics}

We selected three living leaves with robust growth from middle of the crown and measured them by application of OS1P-type portable chlorophyll fluorescence spectrometer produced by OPTISCIENCES Company. The measured indicators were: Y (II) of PSII, ETR, Y (NO), Y (NPQ), and NPQ.

\subsection{Relative electrical conductivity measurements of leaves}

We selected DDS-11AGA-type electrical conductivity meter. First, we clipped leaves of $0.3 \mathrm{~g}$ scrubbed with distilled water, then sucked dry the apparent moisture, and then put them into the conical flask, and then added $30 \mathrm{ml}$ distilled water for standing $12 \mathrm{~h}$ at room temperature, during which we shook and stood it time to time. We measured relative electrical conductivity W1 with the 
preheated conduct meter, then we put the conical flask stuffed with the plug into the boiling water for $20 \mathrm{~min}$ boiling, and then we took it out for cooling it to room temperature, and measured the total electrical conductivity W2. Membrane permeability was calculated according to the formula $\mathrm{W}=(\mathrm{W} 1 / \mathrm{W} 2) \times 100 \%$. Every time we used the electrical conductivity meter, we measured the liquid temperature, and adjusted the constant to set value 1.04.

\subsection{Fuzzy membership function method}

Fuzzy membership function method is a good method for comprehensive evaluation of resistance. The larger the mean of comprehensive evaluation was, the stronger the resistance became [Su Yonghua,2007]. Membership function calculation formula is: $\mathrm{U}(\mathrm{Xi})=(\mathrm{Xi}-\mathrm{Xmin}) /$ (Xmax-Xmin). $\mathrm{U}(\mathrm{Xi})$ is the subordinative function value; $\mathrm{Xi}$ is the stress resistance coefficient of a certain indicator in the same tree species ( $\mathrm{Xi}=$ treatment group indicator value / control group indicator value); maximum Xmax and Xmin are respectively the maximum value and the minimum value of stress resistance coefficient of a certain indicator in the same tree species. If the measured indicator showed a negative correlation with the comprehensive evaluation result, we should use anti-membership function to realize quantitative transformation. Here, the anti membership function calculation formula is: $\mathrm{U}(\mathrm{Xi})=1-(\mathrm{Xi}-\mathrm{Xmin}) /(\mathrm{Xmax}-\mathrm{Xmin})$.

\section{Results}

\subsection{Comparisons of the actual quantum yield Y(II) of PSII in each tree species}

In the condition of light, the Y(II) of PS II could reflect the actual photosynthetic efficiency of plants at present. In the stress environment, organisms in plant were injured by externality, and their photosynthetic capacity was weakened accordingly. As shown in figure 2-1, in regard to the Y(II) of PSII which reflected the actual plant photosynthetic efficiency, four tree species all decreased, in which, the decreasing amplitude of Gordonia axillaris was as much as $65.0 \%$, and decreasing amplitude of Schima superba, Tutcheria championi and Camellia oleifera was within 50\%, as respectively $40.2 \%, 28.8 \%, 42.40 \%$.

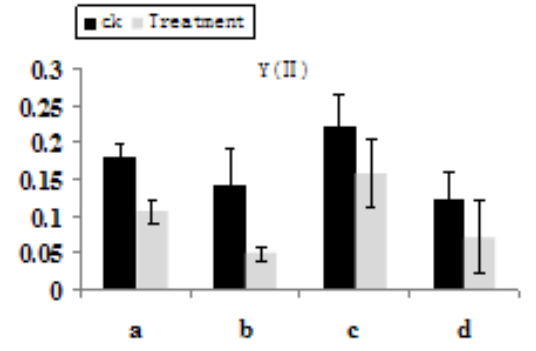

1

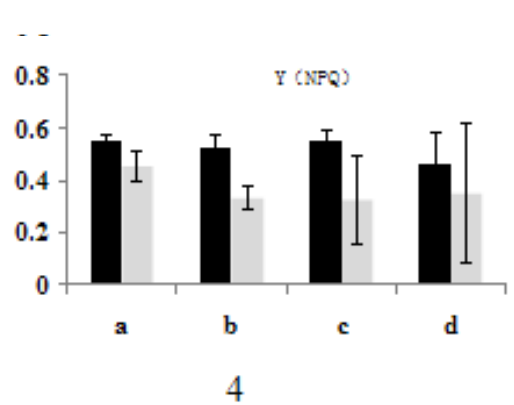

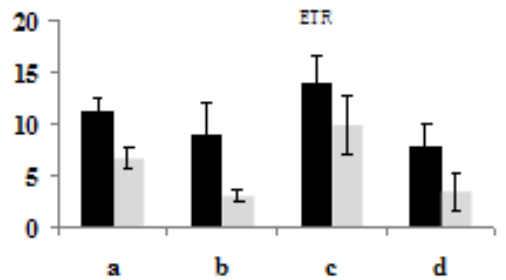

2

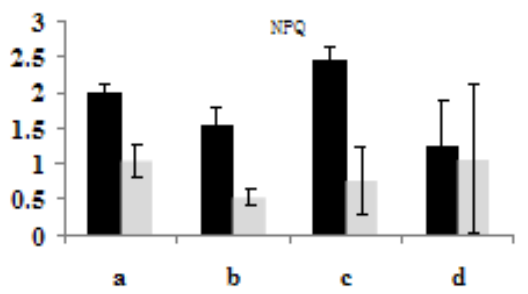

5

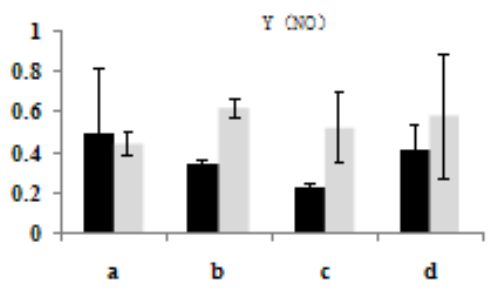

3

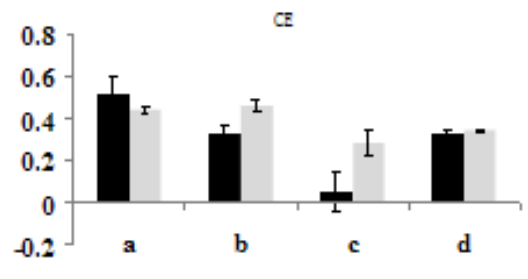

6

Figure. 2 Two hydrogen fluoride concentration gradient (including controls) in four Theaceae tree species .

a, Schima superba; b, Gordonia axillaris; c, Tutcheria championi ;d, Camellia oleifera.

\subsection{Comparisons of relative electron transport rate (ETR) in each species}

ETR, also known as the relative photosynthetic electron transport rate or relative photosynthetic electron transfer rate of PSII, is a parameter of measuring apparent electron transfer conditions of carbon fixation caused by photochemical reaction in the photosynthetic chain under the actual light 
intensity. Because the plants' body were injured in the stress environments, so ETR and Y (II) of PSIIin each species had the same trends, and ETR of each species all showed downtrend (Figure 22 ), in which, Gordonia axillaris and Camellia oleifera declined more than $50 \%$, with respectively, $65.4 \%$, 55.8\%; Schima superba and Tutcheria championi declined within 50\%, as respectively $40.4 \%, 29.0 \%$.

\subsection{Comparisons of non-regulatory energy dissipation quantum yield $\mathrm{Y}$ (NO) in each} species

Y (NO) refers to the condition that the incident light intensity exceeds the acceptable degree of plants, which is an important indicator of photo damage. The larger the value Y (NO) increases, the more serious the plant body damages. As shown in Figure 2-3, with the exception of 9.8\% decline of Y (NO) in Schima superba, Y (NO) in the other species all showed an increased trend, in which Gordonia axillaris and Camellia oleifera respectively increased by $83.7 \%$ and $39.3 \%$, while Tutcheria championi increased by up to $130.7 \%$.

\subsection{Comparisons of regulatory energy dissipation quantum yield $Y$ (NPQ) in each species}

$\mathrm{Y}(\mathrm{NPQ})$ is an auto-regulation indicator which shows the plant requires light protection, and when a plant body is damaged, the ability of regulation will be reduced. As shown in Figure 2-4, Y (NPQ) in the four species declined in varying degrees, in which, Tutcheria championi declined the most, $41.7 \%$, Gordonia axillaris followed, 36.4\%, and Schima superba and Camellia oleifera left behind, $18.7 \%$ and $24.0 \%$ respectively.

3.5 Comparisons of non-photochemical quenching coefficient (NPQ) in each species.

When it is in photosynthesis under illumination, NPQ reflects the ability of the plant dissipating excess energy into heat energy, i.e. light protection. As shown in Figure 2-5, NPQ in each species was in a decreasing trend, which reflected that the ability of the plant dissipating excess energy into heat energy reduced. For the four species tested, Gordonia axillaris and Tutcheria championi declined by more than $50 \%$, specifically $65.4 \%$ and $69.2 \%$ respectively, and Schima superba and Camellia oleifera declined by less than $50 \%$, specifically $48 \%$ and $16.2 \%$ respectively.

\subsection{Comparisons of relative electrical conductivity values in each species}

Relative electrical conductivity is an important physiological and biochemical indicator which reflects the status of membrane system. When the plant is under the condition of stress or other damage, its membrane proteins will be damaged, which later could cause cytoplasm extravasation to increase the relative electrical conductivity and could directly reflect the degree of injury to the plant. The smaller the value of the relative electrical conductivity changes, the smaller the damage will be, on the contrary, the greater the damage of the body, the lager the value of the relative electrical conductivity. As shown in Figure 2-6, except for the decreased relative electrical conductivity value of Schima superba, the other three species showed a rise condition. The relative electrical conductivity value of Schima superba declined by $15.4 \%$, while Gordonia axillaris and Camellia oleifera increased by $39.4 \%$ and $3.0 \%$ respectively, and Tutcheria championi rise increased as high as $460 \%$.

\subsection{Comprehensive evaluation of anti-HF contamination characteristics in each species}

Different plants resist or withstand stress of the external environment in different ways, and the mechanism of anti-fluoride contamination is also very complex, which is affected by many complex interaction of the external morphology, internal structure, physiological and biochemical characteristics, etc.. Many scholars believe that a single anti-fluoride indicator could not fully and accurately reflect the overall ability of plants to adapt to hydrogen fluoride contamination. Therefore, this study used many indicators for comprehensive evaluation. 
Table 1 Stress resistance coefficient values of comprehensive evaluation indicators in four Theaceae species

\begin{tabular}{ccccccc}
\hline Species & $\mathrm{X}_{\mathrm{Y}(\mathrm{II})}$ & $\mathrm{X}_{\mathrm{ETR}}$ & $\mathrm{X}_{\mathrm{Y}(\mathrm{NO})}$ & $\mathrm{X}_{\mathrm{Y}(\mathrm{NPQ})}$ & $\mathrm{X}_{\mathrm{NPQ}}$ & $\mathrm{X}_{\kappa}$ \\
\hline Schima superba & 0.598 & 0.596 & 0.902 & 0.813 & 0.520 & 0.846 \\
Gordonia axillaris & 0.350 & 0.346 & 1.837 & 0.636 & 0.346 & 1.394 \\
Tutcheria championi & 0.712 & 0.710 & 2.307 & 0.583 & 0.308 & 5.600 \\
Camellia oleifera & 0.576 & 0.442 & 1.393 & 0.760 & 0.838 & 1.030 \\
\hline
\end{tabular}

In the comprehensive evaluation method of this study, stress resistance coefficient value of each indicator of the four Theaceae species is shown in Table 1, and each membership function value of each indicator obtained by calculation is shown in Table 2.

Table2 Membership function of each indicator in Theacea species under hydrogen fluoride environment

\begin{tabular}{lllllllll}
\hline Species & $\mathrm{U}(\mathrm{XY}(\mathrm{II})$ & $\mathrm{U}(\mathrm{XETR})$ & $\mathrm{U}(\mathrm{XY}(\mathrm{NO})$ & $\mathrm{U}(\mathrm{XY}(\mathrm{NPQ})$ & $\mathrm{U}(\mathrm{XNPQ})$ & $\mathrm{U}(\mathrm{X \kappa})$ & $\begin{array}{l}\text { Comprehensive } \\
\text { Evaluation }\end{array}$ & $\begin{array}{l}\text { Stress } \\
\text { Resistance } \\
\text { Ranking }\end{array}$ \\
\hline $\begin{array}{l}\text { Schima } \\
\text { superba }\end{array}$ & 0.685 & 0.686 & 0.000 & 1.000 & 0.401 & 0.000 & 0.462 & 3 \\
$\begin{array}{l}\text { Gordonia } \\
\text { axillaris }\end{array}$ & 0.000 & 0.000 & 0.665 & 0.228 & 0.071 & 0.115 & 0.180 & 4 \\
$\begin{array}{l}\text { Tutcheria } \\
\text { championi }\end{array}$ & 1.000 & 1.000 & 1.000 & 0.000 & 0.000 & 1.000 & 0.667 & 1 \\
$\begin{array}{l}\text { Camellia } \\
\text { oleifera }\end{array}$ & 0.625 & 0.264 & 0.349 & 0.769 & 1.000 & 0.039 & 0.508 & 2 \\
\hline
\end{tabular}

\section{Discussions}

In summary, there are individual differences in the anti-HF contamination test of these four Theaceae species. After fumigation, each indicator showed significant fluctuation which implies that each individual has different response speed and mechanism to the external environment and different plant has its own resistance performance to the external hydrogen fluoride contamination, and has its own critical concentration and time. [Gou Xiaohua, 2000].

As for restrictions of the experimental conditions, the experimental material was only seedlings. And the differences of their resistance between big trees are still needed to be explored.

In addition, there are many indicators for measuring resistance of the plant. This study only selected relative electrical conductivity and chlorophyll fluorescence indicators for evaluation. How to choose objective indicators more systematically and to conduct a comprehensive study of resistance is still a problem needing to be further explored.

\section{Conclusions}

This study showed that, under the $500 \mathrm{ppm}$ HF environmental stress, physiological indicators of the four species presented the following changes compared with the control CK:

(1) Y(II) of PSII(z) showed a downward trend, and decrease amplitude was respectively as follows: $65.0 \%$ of Gordonia axillaris $>42.40 \%$ of Camellia oleifera $>40.2 \%$ of Schima superba $>$ $28.8 \%$ of Tutcheria championi;

(2) ETR showed a downward trend, and decrease amplitude was respectively as follows: $65.4 \%$ of Gordonia axillaris $>55.8 \%$ of Camellia oleifera $>40.4 \%$ of Schima superba $>29.0 \%$ of Tutcheria championi;

(3) Y (NO) showed an increased trend except for Schima superba (a decline of 9.8\%), and amplitude was respectively as follows: $130.7 \%$ of Tutcheria championi $>83.7 \%$ of Gordonia axillaris $>39.3 \%$ of Camellia oleifera;

(4) Y (NPQ) showed a downward trend, and decrease amplitude was respectively as follows: 
$41.7 \%$ of Tutcheria championi $>36.4 \%$ of Gordonia axillaris $>24.0 \%$ of Camellia oleifera $>18.7 \%$ of Schima superba;

(5) NPQ showed a downward trend respectively: $69.2 \%$ of Tutcheria championi $>65.4 \%$ of Gordonia axillaris $>48 \%$ of Schima superba $>16.2 \%$ of Camellia oleifera;

(6) In addition to the relative electrical conductivity value of Schima superba (a decline of $15.4 \%$ ), the rest showed an increase trend respectively: $460 \%$ of Tutcheria championi $>39.4 \%$ of Gordonia axillaris $>3.0 \%$ of Camellia oleifera.

The comprehensive evaluation showed that, the anti-HF contamination characteristics of the four Theaceae species in this experiment ranked: Tutcheria championi $>$ Camellia oleifera $>$ Schima superba $>$ Gordonia axillaris.

\section{Acknowledgements}

*Corresponding author: Hongyue Chen, chenyue@scau.edu.cn

This study was partially supported by Foundation of National Forest Public Welfare Project (No. 201004042).

\section{References}

1. AW Davison, JL Shupe, HB Peterson, NC Leone.1984.Fluorides: Effects on vegetation, animals and humans. Paragon Press :61-84.

2. Baker N R.1991.A possible role for photosystem II in environmental perturbations of photosynthesis.

3. Calatayud A, Alvarado J W, Barreno E. 2002. Differences in ozone sensitivity in three varieties of cabbage(Brassica Oleracea L.)in the rural Meditterranean area. Journal of plant physiology159(8): 863-868.

4. Chen Zhuomei, Du Guojian, Miao Yuming. 2008. Resistance and absorption capacity to hydrogen fluoride gas of 38 kinds of landscaping plant in Zhejiang Province. Journal of Zhejiang Forestry College25 (4): 475-480.

5. Dickson R E, Coleman M D, RIEMENSCHNEIDER D E, et al. 1998. Growth of five hybrid poplar genotypes exposed to interacting elevated $\mathrm{CO} 2$ and O3. Canadian Journal of Forest Research28 (11):1706-1716.

6. Fornasiero R B.2001.Phytotoxic effects of fluorides[J]. Plant Science161(5):979-985.

7. Gou Xiaohua; Wang Xunling; Chen Fahu. 2000. Effects of HF fumigation and spraying protective agents on stress ethylene production in wheat.Chin J Appl Environ Biol 6(2):117. In Chinese.

8. Grantz D A, Farrar J F. 1999.Acute exposure to ozone inhibits rapid carbon translocation from source leaves of Pimacotton. Journal of Experimental Botany50(336): 1253-1262.

9. Guera A, Calatayud A, SABATER B, et al. 2005.Involvement of the thylakoidal NADHplastoquinone-oxidoreductase complex in the early responses to ozone exposure of barley (Hordeum vulgare L.) seedlings. Journal of Experimental Botany 56(409):205-218.

10. JIN Minghong, FENG Zongwei, ZHANG Fuzhu. 2000.Effects of ozone on membrane lipid peroxidation and antioxidant system of rice leaves. Environmental Science 21(3):3-5. In Chinese.

11. Leonard H.Weinstein, Ph.D.1977.Fluoride and plant life. Journal of Occupational Medicine19(1):49-78.

12. Mamta Baunthiyal,Arun Bhatt and Shweta Ranghar. 2014.Fluorides and its effects on plant metabolism.Journal

13. Moyer D.Thomas,Ernest W.Alther.1966.The Effects of Fluoride on Plants. Springer Berlin Heidelberg20:231-306.

of Agricultural Technology10(1): 1-27.

14. Pawet M.Pukacki. 2000.Effects of sulphur,fluoride and heavy metal pollution on the chlorophyll fluorescence of Scots pine(Pinus sylvestris L.) needles. DENDROBIOLOGY45:83-88.

Physiol Plant 81(4):563-570. 
15. Su Yonghua. 2007.Construction method and application of geotechnical parameters of fuzzy membership function. Chinese Journal of Geotechnical Engineering29 (12): 1773-1778.

16. Wei Xiaodong; Chen Guoqiang, Shi Dawei, etc. 2012. Drought stress on fluorescence characteristic of photosystem II in Ginkgo. Acta Ecologica Sinica 32 (23): 7492-7500. 